\title{
Partiendo de la angustia : la poesía existencial de Segundo Serrano
} Poncela

Francisca Montiel rayo

\section{Citer ce document / Cite this document :}

Montiel rayo Francisca. Partiendo de la angustia : la poesía existencial de Segundo Serrano Poncela. In: Exils et migrations ibériques au XXe siècle, $n^{\circ} 8,2000.60$ ans d'exil républicain : des poètes espagnols entre mémoire et oubli. Anthologie. pp. 161-174;

doi : https://doi.org/10.3406/emixx.2000.1049

https://www.persee.fr/doc/emixx_1245-2300_2000_num_2_8_1049

Fichier pdf généré le 28/08/2018 


\section{Partiendo de la angustia: la poesía existencial de Segundo Serrano Poncela}

\section{Presentación de Francisca Montiel Rayo*}

Segundo Serrano Poncela (Madrid, 1912-Caracas, 1976) se reveló como escritor después de 1939. Fue un miembro "de la auténtica generación del destierro" para quien la creación literaria tuvo una función fundamentalmente terapéutica: le permitio "sacar afuera esas grandes y pesadas larvas que se mueven en el fondo" del ser humano, contribuyo a evitar que se agitaran "demasiado esas que Santa Teresa llamaba "las mesmas aguas de la vida", hizo algo más llevadera su severa pena de exiliado. Escribir fuera de España le ayudó a restañar, siquiera mínimamente, las profundas heridas que la guerra civil había producido en su ánimo: su inútil duración, sus efectos devastadores, el repugnante recuerdo de su participación en el conflicto, su traumática ruptura con el Partido Comunista, el profundo dolor que le produjo la represión ejercida por los protagonistas de la victoria en el seno de su propia familia y un largo destierro que se inició en Doue (departamento de Seine-et-Marne, Francia) y que transcurrió en República Dominicana (1939-1947), Puerto Rico (1947-1958) y Venezuela (19581976), país donde falleció sin haber podido regresar a España.

\footnotetext{
* GEXEL, Universitat Autònoma de Barcelona.

${ }^{1}$ Tarjeta de S. Serrano Poncela a Guillermo de Torre remitida sin fecha [principios de 1947] desde Ciudad Trujillo, R. Dominicana (Ms. 22830-53 (1), Biblioteca Nacional de España, Madrid).

2 Serrano Poncela, S., "Agonía para ordenar y para crear", Panorama, Santiago de los Caballeros (R. Dominicana), 8 (abril de 1943), p. 8.

${ }^{3}$ Carta de S. Serrano Poncela a Max Aub fechada en Puerto Rico el 19 de enero de 1955 (Archivo-Biblioteca Max Aub, Segorbe, Castellón). He estudiado la relación epistolar que mantuvieron durante años estos dos escritores exiliados en mi artículo "Escribir fuera de España: la correspondencia entre Max Aub y Segundo Serrano Poncela", Alonso, Cecilio (ed.), Actas del Congreso Internacional Max Aub y el laberinto español, vol. I, Valencia, Ayuntamiento de Valencia (Actas y Congresos), 1996, pp. 185-201.
} 
Aunque escribió de forma incesante durante sus primeros años de exilio, su labor no empezó a ser reconocida hasta bien entrada la década de los cincuenta, cuando se publicaron en prestigiosas editoriales argentinas $y$ mexicanas sus primeros volúmenes de narraciones y de ensayos. Para Serrano Poncela, sólo los textos que compuso siguiendo las características de esos dos géneros merecieron ver la luz pública. No sucedió lo mismo con su corta producción dramática ni tampoco con su poesía, aquella vocación juvenil que había compaginado en los años treinta con un intenso activismo político y que prosiguio, después de 1939, marcada por la experiencia de su irreversible destierro. Como hiciera durante lustros Paul Valéry -"uno de los espíritus puros, tan escasos en este siglo $\mathrm{XX}$, que han dignificado la función de pensar hasta hacerla sustantiva y diferencial en el hombre",-, Serrano Poncela prefirió mantener sus versos en un voluntario silencio, un prolongado silencio al que contribuyó no sólo la rigurosidad con la que juzgo siempre su obra sino, sobre todo, la especial significación que tenían para él. Porque la poesía de Serrano Poncela es una poesía escrita en la agónica soledad que, a juicio del autor, debe presidir siempre la creación lírica; contiene "emoción, dolor, ansia",; es el resultado de una constante reelaboración, de un "continuo roerse la cola"" a través del tiempo. "Hilo mis poemas -confesó a Guillermo de Torre- con recoleto amor adolescente. Poesía mía, segregada por "mi realidad de verdad" como diría García Bacca y justificante de este Dasein in der welt que todos tratamos de justificarnos y trascender con "imposibilidad de verdad". Por ello decidió guardar para sí la casi totalidad de su producción poética -todavía inédita-, unos versos en los que se mostró desnudo, unas palabras demasiado íntimas -demasiado doloridas- con las que compuso la declaración atormentada de un republicano vencido, la confesión de un hombre deshabitado que, tras varios

4 S. Serrano Poncela, "Máquinas de pensar y de escribir", Panorama, Santiago de los Caballeros (R. Dominicana), 4, diciembre de 1942, p. 18.

${ }^{5}$ Serrano Poncela, S., "Mensaje de Francia para la poesía (sobre los poetas franceses en el destierro y la reconstrucción de una emoción poética en el dolor)", Panorama, Santiago de los Caballeros (R. Dominicana), 9, mayo de 1943, p. 11.

${ }^{6}$ Carta de S. Serrano Poncela a G. de Torre fechada el 18 de junio de 1947 (Ms. 22830-53 (2), Biblioteca Nacional de España, Madrid).

${ }^{7}$ Carta de S. Serrano Poncela a G. de Torre fechada en Río Piedras, Puerto Rico, el 15 de diciembre de 1949 (Ms. 22830-53 (6), Biblioteca Nacional de España, Madrid). 
años de destierro, pudo levantarse al fin "sobre una tabla rasa de vivencias y valores ${ }^{8 "}$.

Durante esa primera etapa de su exilio, en ese período de desorientación vital, Serrano Poncela escogió algunos poemas de sus cuadernos de notas en los que, según sus palabras, se estaba formando ya "un cementerio de emociones inéditas", - para publicarlos en revistas dominicanas como Panorama y La Poesía Sorprendida. De ellas proceden los primeros cuatro fragmentos seleccionados; el quinto pertenece al poemario Elegía a unas sandalias, doloroso lamento por su pasado y por su presente que Serrano Poncela quiso publicar en España y que finalmente no llegó a difundirse ${ }^{10}$. Se trata en todos los casos de una poesía de marcado carácter existencial que entronca por ello tanto con la tradición española que representa Quevedo como con el pensamiento de Jean-Paul Sartre, en el que el escritor madrileño reconoció haber hallado "el altavoz de una sorda experiencia personal" Los versos muestran su malestar vital, su desaliento, su profundo pesimismo. Serrano Poncela se siente atenazado por la soledad y por el tedio; la tristeza domina su ánimo; la vida es para él un engaño; el clima tropical que está obligado a respirar le excita y le asfixia; la idea de la muerte le asiste. Escribe partiendo de la angustia, sumido en el pozo de una angustia que tiene, en ocasiones, hondas raíces unamunianas. También pueden oírse en los poemas que se transcriben a continuación los ecos de Juan Ramón Jiménez -su lectura predilecta de juventud-, como pueden rastrearse asimismo las huellas del surrealismo, a algunas de cuyas prácticas más habituales acudió Serrano Poncela para expresar mejor sus conflictos internos. Nos encontramos, en definitiva, ante una poesía que refleja de

\footnotetext{
${ }^{8}$ Carta de Serrano Poncela a Guillermo de Torre fechada en Ciudad Trujillo, R. Dominicana, el 18 de junio de 1947, art. cit.

${ }^{9}$ Serrano Poncela, S., "Para una anatomía de la hispanidad. Lo individual, lo solitario y lo irrazonable en el alma nuestra", Panorama, Santiago de los Caballeros (R. Dominicana), 6, febrero de 1943, p. 13.

${ }^{10}$ Sobre el contenido del libro y sobre el proceso que siguio el original en las dependencias de la censura franquista he vertido algunos datos en "Elegía a unas sandalias, poemario inédito de Segundo Serrano Poncela", Pérez Alcalá, Eugenio (ed.), Cultura, historia y literatura del exilio republicano español de 1939. Actas del Congreso Plural "Sesenta años después", vol. III (en prensa).

${ }^{11}$ Carta de Serrano Poncela a Guillermo de Torre fechada en Ciudad Trujillo, R. Dominicana, el 18 de junio de 1947, art. cit.
} 
manera fiel el mundo personal y el mundo literario de Serrano Poncela, un escritor exiliado que siempre procuró contarse "a sí mismo desde sí mismo" 12 ", porque "l'être dehors será siempre le faux être $e^{13 \text { ". }}$

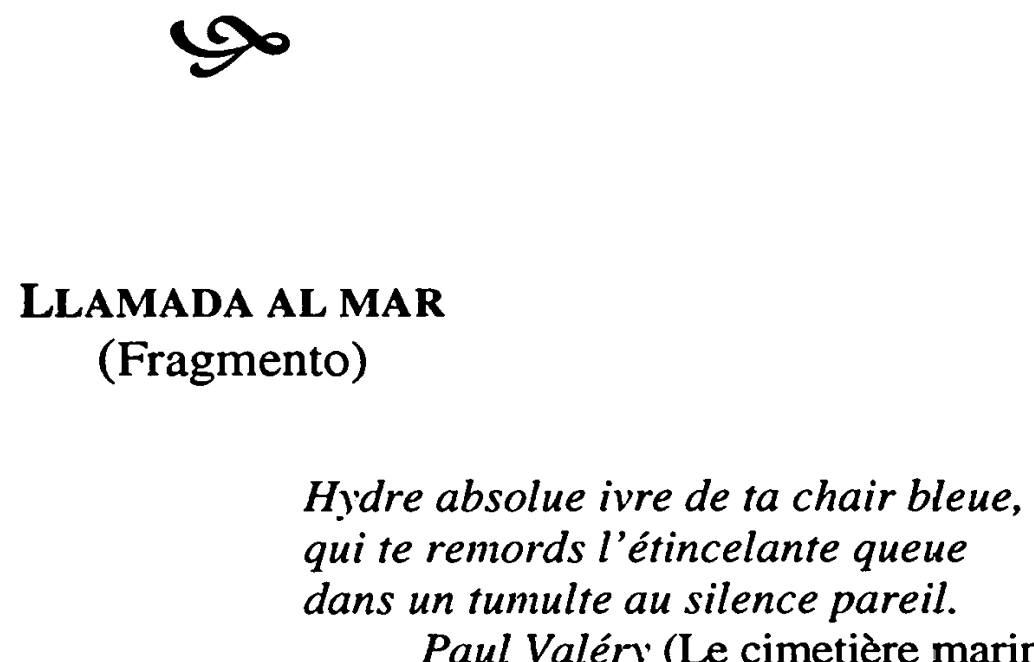

Paul Valéry (Le cimetière marin)

Hermosa y dulce soledad tañida en una trompa de rumor sonoro, líquida selva de silencio y muerte, maravillosa madre de lo oscuro, en el latir pausado de tus venas mi alma pequeña y triste se ha embriagado y ya tus ojos son para los míos.

Por esta vida informe amo y conjuro sobre tu piel rayada de temblores, hija de Dios donde continuamente son y no son las formas increadas promesa de algo, realidad fantasma.

\footnotetext{
${ }^{12}$ Serrano Poncela, S., "El novelista y su sombra”, Ínsula, Madrid, 235 (junio de 1966), p. 1. ${ }^{13}$ Idem.
} 
Aquí estoy yo, de pensamiento y tierra, soñando ser y como tú en mi alma, yendo y viniendo de la luz al fondo con las dos manos sin cesar tendidas hacia las sombras de lo inaprensible.

Déjame ver tu manantial de gloria donde se nutre inacabable fuerza y esa continua realidad de peces hechos de viva flor de pensamiento y luces ágiles.

Quiero dotar de escamas mis delfines y hacerlos flechas sobre el agua mía.

¡Qué soledad de mar mi vida oscura!

¡Qué hermosa y llena soledad de agua mi retenida fuerza bajo un cielo inmóvil sin calor y sin medida!,

gloriosa vida mía en su silencio; tú y yo lo mismo, mar, los dos bien solos creando y recreando nuestra angustia.

Tú y yo -mi mar, tu mar-también sin tregua como las olas que en su mismo centro son a la vez, sin ser, forma y espuma. [...]

Enero, 1942

(Panorama, Santiago de los Caballeros, R. Dominicana, 3, noviembre de 1942) 
Poema en 15 estaciones

(Fragmentos)

I

INTENTARÉ DECIRTE ¡oh dulce y suave sombra! algo del misterioso resonar de mi vida en parte la verdad que yo sé de esta vida tan tristemente mía, y serán mis palabras como un viento sonoro y detrás otros vientos con ecos y campanas sobre un triste horizonte cargado de caballos que tuvieron un día temblor en las pezuñas Es así mi comienzo: sus membranas abiertas como el que llega tarde a una postrera cita mi corazón galopa (algún presentimiento el latir angustiado de algún presentimiento) mi corazón galopa (y algunas veces pienso en la oscura marea que bate los destinos) mi corazón galopa (y es este pensamiento dolor irremediable hundido en el silencio) Vivir es un acecho de peligro entre rosas disfrazado de rosas, un sueño delicado que apenas nace muere, el eco de un bramido que se pierde entre espigas, algo inasible, en fin, a veces como cálida melodía que fuese un eco en melodía. Quise decir peligro y rosa y ahora digo peligro disfrazado de rosa y de mentira. [...]

\section{IX}

NO SÉ POR QUÉ, mas tengo como un sabor a muerte un olor hechizado; tremendo olor a muerte como un color sonámbulo que vive al lado mío que quiere visitar quizá esas tierras lentas 
de las que nadie vuelve

llenas de pensamientos, cenizas y alunados.

Acaso estoy jugando con mis zonas de lágrimas

insensible al sonar de un pecho dilatado

y apagando una hoguera vertical y encendida

que tú, mi dulce sombra, mantenías perenne.

[...]

\section{XII}

DE PRONTO algo se agrieta

todo haciéndose roto, lamentable y oscuro

como una cueva húmeda, lo mismo que una cueva

entre paredes altas y salitre y silencio

y me siento bajando

y una angustia de ahogo, de carbón y de ahogo

y una seguridad de haberme desprendido

de no ser nada, nada, conforme voy bajando.

Hay sin embargo un dulce, delicado consuelo

en ver que los demás también van mundo abajo

iguales, desgraciados, aburridos, voraces

miles de ojos sin sangre que vamos mundo abajo

porque la vida es esto, un fracaso de plomo

una carne adornada de lívidas espinas

una boca de trompa, unas manos dormidas

todo tan violento, rodando mundo abajo

como si nos odiáramos con cariño de hermanos

como si nos odiáramos fraternalmente.

[...]

\section{XV}

ESCUCHA ESTAS mis últimas palabras: lento y lento sin tregua en su amoroso y cálido goteo algo se va callado por mis venas de hastío, 
está yendo; se fue por un mar solitario y quieto, entre las olas que mecen encantadas al barco de la muerte.

(Panorama, Santiago de los Caballeros, R. Dominicana, 10, junio de 1943)

\section{SALMO NÚMERO 5 \\ (Fragmento $^{14}$ )}

A veces, cuando siento las pisadas de la angustia cerca de mí, lo mismo que si la sangre se detuviese en el cuello y todo me parece entre los hombres fiesta de miseria es cuando grito: ¡Dios mío, Dios mío, Dios mío!, ¿por qué me has abandonado? Ese rebaño de negros toros viene implacable desde el extremo del horizonte Las aguas de la fe se han derramado y en vano es el beberlas con la boca pegada en el suelo Descoyuntaste los huesos y ahora es difícil recomponerlos el corazón se ha derretido como una mezcla de cieno y cera. ¿Dónde están mis entrañas?

¿Puedo llamarte a juicio por este dolor oscuro que ocupa el lugar antiguo de mis entrañas? Secaste mi vigor y la lengua se siente pegada al cielo de la boca. Desesperado me hallo nadando en el polvo de la muerte los perros me rodean agujeros de hielo atraviesan mis manos y mis pies y si quisiera contar la osamenta desperdigada no habría bastantes números para llenar mis días y mis noches. Dame la espada de mi vida dame otra vez mi alma solitaria y hermosa, dorada como una [paloma escucha mi voz llorando a través de los cuernos de los uros. $[\ldots]$

${ }^{14}$ A partir de este poema, la puntuación de S. Serrano Poncela, quizás voluntariamente, se vuelve aún más incierta. 


\begin{abstract}
A la orilla de esta fuente donde suena la angustia como un cadáver olvidado de todos como un vaso roto que siente las grietas de su arcilla y el miedo caminando alrededor con sus manos de seda alrededor mío.
\end{abstract}

Aquel verdor se ha vuelto sequedad de verano ni tengo cuerdas en el salterio ni canciones alegres para tus coros sólo los almacenes repletos de animales extraños innúmeras, sucias cosas muertos antiguos, blasfemias y fornicaciones atravesándote con sus lanzas, todos ellos manteniendo combate A veces me llevan en el viento como un tamo impalpable acosado a lo oscuro por las terribles alas de tus ángeles con el alma cavada, llena de resbalones crujiéndome los dientes (no es mi voz, no, brillante y limpia, quien se lamenta ahora) pero no me reprendas con tu ira tu indignación ardiente no me consuma ni me castigue hieden mis llagas, mi iniquidad transpira me has encorvado y humillado ante los hijos de los cielos rujo entre dientes por abceso que tuvo mi razón y mis suspiros no se te ocultan. ¿Qué más esperas, oh Dios, qué más esperas? Librame de las angustias y dubitaciones sálvame entre estos hombres que se precipitan en los ríos no me dejes entre ellos, con sus íconos y sus túmulos hazme único, hijo del perdón y de la buena nueva levanta tu mano que reposa con terrible azote sobre mis pálidos lomos no ignores a mis lágrimas, que no soy extranjero pon en mi boca un nuevo cántico recomponme en el orden que tu ley está viva como una planta en medio de mi corazón.

Santiago de los Caballeros, R. Dominicana (La Poesía Sorprendida, Ciudad Trujillo, Isla Española-R. Dominicana, V, febrero de $1944^{15}$ )

${ }^{15}$ Reimpresión facsímil: San Pedro de Macorís, R. Dominicana, Universidad Central del Este (Serie Literaria 15, volumen LXX), 1988, pp. 53-55. 
EL AHOGADO

(Fragmento)

Llora el ahogado, llora debajo del agua silencioso llora golpeando sus mejillas

La líquida montaña le arrastra, le anega llora el ahogado en abandono, frío

Por los campos marinos, temeroso, llora sin sombra ni huellas para acompañarle

Hasta el alma llega la inundación, el barro tapa su garganta, despiadado le ahoga

Una palabra dice, un granate de fuego entre sus labios duros, desesperados

Una gran voz. El agua silenciosa, inmóvil grave llanura de agua le somete al silencio

Entre aletas viscosas, minerales, monstruos silencioso devora remordimientos.

Se mueven las arenas y los gusanos el ahogado lleno de peces y lágrimas.

Antes cantaba el sol en plácidas llanuras sobre las viñas la canción de sus jugos

Antes de ser raído, cuando aún no vestía la piel de puerco, antes del diluvio.

\section{$[\ldots]$}

Dios de la milagrosa barba, santifica presta una vez tan sólo tu voz al muerto 


\begin{abstract}
$\mathrm{Al}$ ahogado que llora por los campos verdes al ahogado que llora en abandono, frío

Si no le ven, si a nadie sirve su ejemplo porque tu Ira y tu Piedad no quieren

Si vive a solas inservible, oscuro con su espinazo roto para siempre

Chorreando su alma de ignominia en la líquida gruta del olvido

¿Podrás, Señor, en juicio demandarle? ¿podrás, Señor, gozarte en Tu Justicia?
\end{abstract}

La Española, febrero 1946

(La Poesía Sorprendida, Ciudad Trujillo, Isla Española-R. Dominicana, XX, enero-marzo de $1947^{16}$ )

\title{
DISCURSO DEL MÉTODO
}

(Fragmento)

\section{I}

Todo sucede en prosa, una diaria prosa en subjuntivo

Los geranios y las disenterías

Cantan la rama verde, el mirto verde, la corona del santo

Los vendedores de periódicos

Todo sucede en prosa y son las once de la mañana

Bajo bombardeos de radio y corpúsculos cósmicos

Este sol alimenticio, goloso, que excita y procrea

Son las once de la mañana, puede que sean las once de la

[mañana

Una larga mañana de marzo

Donde caben la conferencia atómica y el desayuno

${ }^{16}$ Reimpresión facsímil, op. cit., pp. 329 y 331. 
Una larga mañana sobre un lugar de la tierra

Es igual, da lo mismo, todo sobre la tierra, un lugar sobre la

[tierra

Ante mí, silenciosos escriben y sus tiernas cabezas

Sus cabezas adolescentes, sus cabezas vacías de vida

Me conturban, me hieren

Sus ojos adormecidos por el tedio, los opios pedagógicos

Atrapan invisible sabiduría, pescan en el espacio inmóvil

Sus perezosas plumas, sus lápices bovinos

Suben y bajan perezosos por el papel, por el cráneo

La maquinaria vegetal en la mañana del día crece

Bombea indiferente, devorando pasa y se consume

Esta larga mañana de marzo; otra tendida, inmóvil mañana de

Una mañana más y bajo por la rampa del embudo

[tedio

Y cavo silencioso mi pequeño pedazo de tiempo

Con la mano que rasca maquinal y también maquinal escribe:

Una hora. Examen comenzado

Problema de estilo: alusiones y elusiones

En la poesía de Don Luis de Góngora

\section{II}

¡Oh devoradora, invisible, generosamente callada!

(Me detienen las admiraciones

Porque soy un hombre de nuestros días, un advenedizo

Alguien que no puede cantar, que susurra torpemente

Asegura sus palabras con tornillos racionales

Antropófago de sí mismo, de autoanálisis

Sus proteínas, su cáscara pura, su materia)

¡Oh devoradora! Me sentía vivir y viviendo

Y digo: ¡Oh devoradora, invisible, callada

Tú, mi vida! La mágica rueda de mi vida girando, girando

Por el Tiempo. Mi vida girando. Lo que canto es mi vida

( $Y$ me detiene una sencilla admiración, un signo, una vergüenza 
Una ropa interior depositada, eso es todo

Porque difícil es morir, amigo Varo

Más difícil vivir, más difícil todavía)

[...]

En estos largos días de calor y de tedio

En estos lentos días en que la tierra se desvencija y pare

En esta premonición de estío, en este subterráneo renovar de

[materia

Yo pienso tan extrañas historias de sol y muladares

$Y$ rosas y perfumes y ángeles y vientres

Mientras avanzo por el agua del tiempo fecundándose

Yo pienso en estos días, todos los días pienso, algo pienso

Piensa mi pensamiento, piensa cómo se piensa

En estos largos días, en estos días diarios, en su estela

Arrastrando una estela, una cola de piedra

Pienso, una majestuosa estela de piedra

Una estatua de Tiempo

Una inmóvil estatua de tiempo que fui yo, que no es mío

Mientras la tierra crece, la valva pare, la oruga vuela

Gira la rueda, gira y yo doliente

Y digo:

Hay en lo ajeno y fundante del Ser una continua tentación para

En el ombligo del Ser, en su relámpago

[el hombre

Hacia detrás y hacia delante

Hacia el ángel y hacia el excremento

Heme aquí con mis alas de estaño

Mi grávida materia, mi pura conciencia entre paréntesis

Mi estufa y mi abandono

$\mathrm{El}$ ángel guarnecido de tentaciones me espera

Nutre de luz, guiña sus ojos, se expresa y me exprime

Tiende su mano, su sortija, su cítara, su boca húmeda

$\mathrm{Su}$ ambigua resistencia y sube

$Y$ suben las rosas y el perfume y legiones de hormigas

$Y$ yo en su bella trampa suspirando, dormido

$Y$ sube atravesando tentaciones y yo diciendo: no 
Dulcemente diciendo y negando

Una vez y otra vez y mi cuerpo caído caía

Mi cuerpo anclado en su materia

La presencia amenazante de mi cuerpo, su dura patencia

Descomponiendo, asimilando; el ángel suspiraba lejano

Suspiraba cada vez más lejano, suspiraba, la sombra del ángel

Suspiraba, el recuerdo del ángel perdido suspiraba.

$[\ldots]$

\section{VIII}

Estas y otras canciones discurro

La primavera llegando lentamente

Una bomba de lluvia lava los lirios y los gladiolos

Estas y otras canciones el ángel de mi cuerpo

Su barba, sus mandíbulas, sus grandes alas

Su calvicie prematura

Sus pequeñas historias de amor y aun menos agradables

$\mathrm{El}$ ángel de mi cuerpo pregunta y escribe.

[...]

(Elegía a unas sandalias, poemario inédito, 1952) 